\title{
«Son prácticamente casos perdidos». Trata de personas y respuesta judicial en Madre de Dios, Perú*
}

\author{
Diego Tuesta**
}

\footnotetext{
" Este artículo es posible gracias al apoyo de George B. Zachary, asesor de la Embajada Británica en Lima; Jorge Chávez Cotrina, coordinador de las Fiscalías Especializadas contra la Criminalidad Organizada; Luis Alberto Sánchez, fiscal provincial; Juan Huambachano, gerente del Observatorio de la Criminalidad del Ministerio Público; Robin Cavagnoud, Eduardo Dargent, Maritza Paredes, Bertha Prieto, Jaris Mujica, Yván Montoya y Joel Jabiles, docentes e investigadores de la Pontificia Universidad Católicadel Perú. Agradezco también a Máximo Sozzo, por cuyos seminarios pasaron versiones preliminares de este trabajo. Y, finalmente, a Clara Núnez por el soporte necesario para afrontar este y otros desafíos.

** Licenciado y magíster en Sociología por la Pontificia Universidad Católica del Perú, y miembro del Grupo Interdisciplinario de Criminología. Doctorando y afiliado en el Centro de Criminología y Estudios Sociolegales de la Universidad de Toronto, Canadá. Correo electrónico: diego.tuesta@mail. utoronto.ca
}

Fecha de recepción: 10/09/2019. Fecha de aceptación: 01/12/2019. 
«Son prácticamente casos perdidos». Trata de personas y respuesta judicial en Madre de Dios, Perú

\section{RESUMEN}

La literatura empírica sobre judicialización de la trata de personas es relativamente escasa en Sudamérica. El artículo aporta evidencia sobre diligencias judiciales contra este delito en Madre de Dios, región emblemática de minería artesanal en Perú. Demuestro que la actuación fiscal obedece a un conjunto de lógicas de acción, en contraste con narrativas que la interpretan como resultado de elecciones racionales. Dicha constatación permite abordar el problema de la selectividad penal, o por qué los fiscales prioriza algunos casos en vez de otros. Si bien la discrecionalidad que estos actores disponen es un importante para explicarla, existen factores poco discutidos — por ejemplo, la cultura organizacional de los grupos profesionales que conforman el sistema de justicia— que influirían también en dicho comportamiento. Esta exploración permite promover algunas categorías novedosas en la sociología del derecho.

Palabras clave: criminalización, experiencia social, pruebas, selectividad penal, trata de personas.

«These are basically lost cases». The prosecution of human trafficking in Madre de Dios, Peru

\section{Abstract}

Research on the prosecution of human trafficking is scarce in South America. This paper provides evidence of criminal procedures for this offense in Madre de Dios, one of Peru's emblematic gold mining enclaves. I demonstrate that prosecutors' behaviour is shaped by a plurality of actions, which contrasts contemporary scholarship focus on rational choice theory. I also shed light on penal selection patterns, or why prosecutors prioritize some cases instead of others. Although discretion is certainly a key aspect, I find that other variables_-such as the cultural organization within justice practitioners-play an important role to explain the aforementioned behaviour.

Keywords: criminalization, social experience, challenges, penal selection, human trafficking. 


\section{INTRODUCCIÓN}

Superar adversidades es una constante de la experiencia humana. Martuccelli (2007, p. 102) señala que todo individuo atraviesa pruebas; digamos, situaciones difíciles y dolorosas. La noción de adversidad, o prueba, tiene una connotación que trasciende al individuo. $Y$ es que muchas pruebas son estructurales: se imponen sobre nosotros "desde afuera», como circunstancias ajenas a nuestra elección ${ }^{1}$. No todo individuo está sometido a las mismas pruebas ni cuentan con los mismos recursos para salir airoso, de lo que sigue que las capacidades para elegir entre cursos de acción no están igualmente distribuidas. Es interesante pensar, quizá algo obvio, que las adversidades no se reducen a los individuos. Los Estados, por ejemplo, son actores con tremendos desafíos que cumplir: reducir las desigualdades, neutralizar la criminalidad, mantener el orden social. No es novedad decir que el Estado las afronta mediante funcionarios concretos (un cuerpo administrativo, ver Weber, 1993), cuyas acciones muchas veces dependen de los recursos puestos a disposición, la naturaleza del desafío o el sesgo de una política pública, etc.

En este artículo describo una parte — quizá muy pequeña— de la vida profesional de un grupo de fiscales y operadores de justicia: funcionarios dedicados a combatir la trata de personas en Madre de Dios, región de Perú donde prolifera la minería de oro de pequeńa escala ${ }^{2}$. Desarrollo un inventario (no exhaustivo) de los desafíos que estos funcionarios atraviesan, el mismo que sirve para dialogar con una lectura extendida en la literatura: que la discrecionalidad de los operadores de justicia se reduce a un problema de elección racional. Esta discusión me sirve como un camino de ensayo para explicar el porqué de la selectividad penal. ¿Por qué los fiscales casos de trata con ciertas características? ¿Qué sentido tiene la selectividad penal en el contexto de industrias extractivas informales?

El texto se divide en cuatro secciones: introduzco primero algunas notas metodológicas; luego, describo la política criminal contra la trata en el Perú y el contexto en que se desarrolló mi trabajo de campo; tercero, presento una breve reseńa de la literatura especializada; finalmente, discuto mis hallazgos (que prefiero llamar «indicios») y planteo unas breves conclusiones.

\footnotetext{
1 Araujo y Martuccelli (2010, p. 6) proponen la siguiente definición: «las pruebas son desafíos históricos y estructurales, socialmente producidos, culturalmente representados, desigualmente distribuidos, que los individuos — todos y cada uno de ellos — están obligados a enfrentar en el seno de una sociedad. La noción de prueba propone, pues, como tantas otras, una articulación entre los procesos estructurales y las experiencias personales, pero allí donde otras nociones, como, por ejemplo, la teoría de la socialización, buscan establecer vínculos necesarios (y muchas veces incluso inferir conclusiones microsociológicas desde consideraciones macrosociológicas), el estudio por las pruebas deja siempre abierta, y, por ende, problemática, esta relación.

2 Para una lectura centrada en la minería artesanal en Madre de Dios recomiendo revisar los trabajos de Cortés-McPherson (2019), García Morcillo (1982) y Mujica (2014).
} 


\section{Metodología}

Esta investigación data de inicios de 2016, cuando, a solicitud de la Embajada Británica en Lima, elaboré un diagnóstico cualitativo sobre los problemas que afronta el proceso penal contra la trata de personas en Madre de Dios ${ }^{3}$. Tuve la oportunidad de entrevistas a fiscales, funcionarios de medicina legal, policías y trabajadores sociales. Me concentré en el personal adscrito a la Fiscalía Provincial Especializada en Delitos de Trata de Personas y del Instituto de Medicina Legal y Ciencias Forenses de Madre de Dios, tanto el personal judicial como los superiores jerárquicos. A fin de validar mis observaciones, en 2016 hice una segunda ronda de entrevista con los fiscales ${ }^{4}$. Ese mismo año entreviste también — con el objetivo de poner en consulta mi análisis - a especialistas legales y sociales en la materia. Mi trabajo sumó veinticinco entrevistas semiestructuradas, de las cuales diecisiete se disponen sobre el personal fiscal, de medicina legal y trabajadores sociales 5 .

La unidad de análisis no es otra que la «experiencia» de los fiscales. No cualquier experiencia por supuesto, sino aquella producto de liderar operativos contra la trata de personas, proceso en el que distinguimos tres clases de desafíos: desafíos para diseñar y ejecutar operativos exitosos contra la trata de personas (un operativo es exitoso cuando deriva en la captura de imputados o en el rescate de víctimas), desafíos para judicializar los casos identificados, y un tercer desafío que tiene que ver con la gestión de víctimas y de testigos.

¿Qué entenderemos por experiencia? Dubet aporta una noción útil, al definir la sociología de la experiencia como «una combinación de lógicas de acción, lógicas que vinculan al actor a cada una de las dimensiones de un sistema» (Dubet, 2010, p. 96). El presupuesto es que la experiencia no se reduce a una sola lógica de acción, sino que comprende una pluralidad de acciones en el sentido weberiano. Tres operaciones intelectuales se necesita para obtener un registro de la experiencia: la primera

\footnotetext{
3 Jaris Mujica y Bertha Prieto formaron parte del equipo consultor, y fueron responsables del trabajo de campo y del análisis en la primera fase del estudio entre enero y abril de 2016.

4 Además, intentamos contrastar las entrevistas con estadística e información documental. El 85\% de entrevistados firmó un protocolo de consentimiento (Comité de Ética de Investigación con Seres Humanos y Animales, 2017). Cada entrevista duró entre 45 y 60 minutos.

5 En el caso de los fiscales, se entrevistó al presidente de la Junta de Fiscales de Madre de Dios, al fiscal provincial encargado de la Fiscalía Especializada en Delitos de Trata de Personas y a prácticamente todo el personal fiscal a su cargo $(n=4)$. En el caso del Instituto de Medicina Legal, también comprendimos a superiores jerárquicos y al personal subordinado $(n=11)$. En el caso de la Policía Nacional y de otras instituciones, fue más complicado replicar este ejercicio, pudiendo solo entrevistar al jefe encargado. Con todo, es de recordar que el foco de la exploración tiene que ver con investigaciones preliminares, en las cuales fiscales y médicos legistas son los protagonistas. Dada nuestra atención a investigaciones preliminares (además de algunos condicionamientos presupuestales), donde los fiscales son protagonistas, se optó por no entrevistar a jueces.
} 
es describir el tipo de lógica que los actores dejan entrever en sus relatos; la segunda operación es comprender estas lógicas como un proceso de construcción histórica (donde el actor es el protagonista, obviamente), antes que como un hecho dado e incontrovertible; la tercera operación, dice Dubet (2010, p. 100), es interpretar cómo estas lógicas de acción individual se articulan con propiedades más generales de los sistemas sociales, de lo que sigue esta importante intuición sociológica: que la estructura de la acción puede no pertenecer del todo al actor.

Mi indagación tuvo limitaciones, que hoy interpreto como una oportunidad para profundizar el tema. Cuando salí a campo en 2016, no consideré la importancia la cultura de los mencionados grupos profesionales. Ignoraba que tuviese un peso tan significativo en el desarrollo del proceso penal. Esta clase de factores merecen mayor tratamiento a futuro. Por otro lado, no tuve fortuna - o el peso políticopara acceder a datos sensibles del Ministerio Público. Sin duda hubiera sido útil estudiar el plan operativo que la Fiscalía Provincial Especializada diseña con la Junta de Fiscales Provinciales (se argumentó que era información reservada), y corroborar los objetivos de la entidad a nivel local. Otros indicios me fueron también esquivos. Los entrevistados, por ejemplo, exponían razones por las que fracasan algunos operativos. Hubiera sido pertinente acceder a sus archivos y determinar el porcentaje exacto. La prudencia analítica es, en consecuencia, el tono dominante de mis observaciones.

\section{2. ¿CON QUIÉN CONVERSA ESTE TRABAJO?}

La literatura empírica — principalmente en lengua inglesa - presenta dos líneas de interés: documentar los obstáculos que fiscales de distintos contextos nacionales afrontan en sus diligencias; segundo, dar cuenta de factores que explican la decisión de acusar o archivar cargos penales. Se trata de doslíneas de interés pertinentes para evaluar políticas públicas y leyes en este terreno. La literatura mantiene una premisa basada en los trabajos de Albonetti sobre discrecionalidad. Convincentemente, esta autora probó que los fiscales tratan de evitar la incertidumbre procesal (Albonetti, 1986, 1987). Qué entender por incertidumbre es una pregunta necesaria, teniendo que ver con la probabilidad de que un juez emita sentencia condenatoria.

La teoría es, entonces, concluyente. Un fiscal priorizará casos con evidencia suficiente sólida como para anticipar una sentencia condenatoria. La disponibilidad de evidencia reduce la incertidumbre procesal. En este comportamiento selectivo, desde luego, intervienen factores que un poco escapan al control de los actores: muchos fiscales trabajan con limitaciones presupuestales, de personal y en condiciones de sobrecarga procesal. Asumir un caso complejo dificultaría la gestión de muchos otros. No menos importante: muchos fiscales piensan que la acumulación 
de sentencias condenatorias redituará beneficios de carrera, por lo que resulta estratégico ocuparse de casos "fáciles» de resolver ${ }^{6}$.

A fin de hacer un breve balance de la literatura, inicio citando los estudios de Farrell y colaboradores, los cuales aportan detallados diagnósticos sobre obstáculos para judicializar la trata de personas en Estados Unidos (Farrell y Cronin, 2015; Farrell, McDevitt y Fahy, 2008; Farrell, Owens y McDevitt, 2014; Farrell, Pfeffer y Bright, 2015; Farrell y Pfeffer, 2014; Tiwana, Bass y Farrell, 2015). Estos autores problematizan un hecho comprobado en diversos contextos nacionales: que realmente son pocos, muy pocos, los casos de trata de personas identificados y juzgados anualmente. Mediante una muestra, determinan que siete de cada diez fiscales en dos estados de ese país prescinden de imputar cargos por trata y más bien utilizan tipos penales alternativos, que solo $17 \%$ de personas detenidas son luego acusadas por el delito de trata ${ }^{7}$ y que más del $50 \%$ de casos compromete de alguna forma a menores de edad (Farrell et al., 2014). El sistema penal reproduce este comportamiento pues existen barreras legales e institucionales, entre otras vinculadas a percepciones extraordinariamente estigmatizantes de los operadores hacia las víctimas (los autores a veces usan la expresión «attitudinal barriers» y en otros casos «cultural blinders», ver Farrell y Pfeffer, 2014; Farrell et al., 2015).

Los obstáculos legales son de dos tipos. Unos tienen que ver con la carga probatoria excesiva que, a criterio de los operadores, las leyes de trata exigen. En muchos sistemas, el fiscal debe acreditar la conducta de un imputado, los medios que anulan la agencia de una víctima y, por último, fines específicos de explotación. Entonces, a decir de varios, esto genera que imputar por trata sea más costoso en tiempo y recursos (Matos, Gonçalves y Maia, 2017; van der Watt y van der Westhuizen, 2017). De allí que algunos usen figuras penales alternativas, de menor pena, para «salirdel paso" y aliviar la carga de trabajo ${ }^{8}$. Una segunda barrera es la dependencia en el valor incriminatorio

6 Como indican Farrell, Owens y McDevitt (2014), «El éxito en materia de persecución penal se define en términos de obtener una sentencia. Lograr un buen promedio de sentencias (batting average), entendido como el ratio de encarcelamiento versus absoluciones, es el principal criterio del que depende el éxito profesional, prestigio y la movilidad del fiscal» (p. 163, traducción propia). Aquí tenemos de por medio una interpretación sobre las decisiones que proviene de la teoría de elección racional y de la psicología conductual. Cierto es que algunos trabajos han enriquecido esta mirada, no reduciendo el comportamiento de los fiscales a cálculos racionales. Farrell y colaboradores, por ejemplo, identifican la existencia de «barreras actitudinales»: valoraciones negativas que algunos operadores desarrollan sobre las víctimas de trata de personas, y que explicaría el sobreseimiento en casos donde ellos juzgan que estas han tenido "comportamientos de riesgo".

7 Farrell et al. (2014) estudian 140 casos provenientes de 12 condados en los Estados Unidos, y 166 entrevistas a operadores de justicia. De todos los casos, $85 \%$ son categorizados como trata con fines de explotación sexual y $11 \%$ laboral.

8 «Las entrevistas con policías y fiscales iluminaban áreas de incertidumbre en la persecución al amparo de las leyes antitrata, incluyendo confusión sobre cómo definir los elementos constitutivos de este delito, 
del testimonio de las víctimas (Farrell et al., 2014; Reid, 2013; Wilson y Dalton, 2008). Probar el delito de trata de personas y obtener testimonios con valor probatorio es un desafío mayúsculo en casi todos los sistemas penales, al margen de variaciones presupuestales y de personal. Farrell et al. (2014) y Matos et al. (2014) prueban que estas condiciones - en particular, las cuestiones relativas a pruebas convincentesabren un «escenario procesal incierto» que promueve las dos clases de respuesta ya mencionadas: el sobreseimiento o el uso de tipos alternativos al de trata.

Las barreras institucionales implican los siguientes problemas: personal carente de entrenamiento, programas deficientes para asistir a víctimas, y modestos recursos tecnológicos son características in extenso documentadas en varios sistemas penales? Por ejemplo, luego de aplicar pruebas de conocimiento, Mapp, Hornung, D’Almeida y Juhnke (2016, p. 12) encontraron que siete de cada diez fiscales en Estados Unidos manejaban definiciones imprecisas sobre trata de personas. La literatura coincide que los «mejores resultados judiciales» ocurren en contextos nacionales muy específicos, por ejemplo donde los gobiernos locales logran armar cuerpos policiales y de fiscales altamente entrenados y con funciones investigas ad hoc contra el fenómeno discutido, como prueban Huff-Corzine, Sacra, Corzine y Rados (2017).

Refiramos, por último, a las «barreras actitudinales». Estas consisten en creencias generalizadas, cargadas de escepticismo, que los fiscales mantienen sobre el resultado judicial y sobre las víctimas. A estas no pocas veces se les adjudica «conductas de riesgo" que, según los fiscales entrevistados, hacen dudar de su victimización, Reid (2012) aporta pruebas sobre esta problemática, determinando que cerca de 400 menores fueron arrestados por promover la prostitución en Estados Unidos. En una frecuencia cuyo total el autor no explicita, los operadores inducen a las víctimas que se inculpen como responsables de promover la prostitución. De esta forma son derivadas a programas de asistencia social, con lo cual el caso queda formalmente resuelto. Si bien esta estrategia sirve para reducir la carga procesal, facilitando que los fiscales se ocupen de otros casos, genera cuestionamientos porque transfiere la carga de responsabilidad penal sobre la víctima.

Pasando a Sudamérica, hay quienes argumentan que la judicialización de la trata tiene efectos colaterales como la sobrecriminalización del trabajo sexual y el aumento de la revictimización. Al respecto, Daich y Varela (2014) emplean la categoría «industria del rescate (2005b, 2009; citado por Daich y Varela, 2014, p. 75) para describir la prioridad asignada al rescate de víctimas; más concretamente, el énfasis policial —a veces exacerbado—sobreoperativos de interdicción y expansión

tales como la «coerción» o la supuesta necesidad de corroborar el traslado de la víctima» (Farrel y Pfeiffer, 2014, p. 50). Asimismo, la distinción entre explotación laboral, trabajo forzoso y trata de personas, resultaba poco clara. Las dificultades para clasificar las experiencias de víctimas confunde a la labor policial».

9 Conviene preguntar si esto tiene que ver con que las reformas antitrata son relativamente nuevas. 
de servicios asistenciales. Estos últimos dependen de «la ampliación del número de víctimas» y de "los límites de la categoría «trata» hasta alcanzar cualquier oferta de servicios sexuales» (Daich y Varela, 2014, p. 75). Se documentan casos en Argentina donde trabajadoras sexuales son clasificadas como víctimas de trata en el marco de un proceso penal, recibiendo asistencia social pero también, en una frecuencia no determinada por estos autores, criminalizadas mediante sanciones comerciales por trabajar en casas «sin licencia» (Daich y Varela, 2014).

Abadía (2019) presenta evidencia similar en Colombia. Una revisión de expedientes entre 2008 y 2010 le permite corroborar que muchos fiscales y jueces tienen dificultad para discernir los fines de explotación de la trata de personas respecto de los propios a prácticas de prostitución convencional. Algunos jueces argumentan que la finalidad de explotación es consustancial a todo intercambio sexual por dinero, con lo cual se da «una ampliación del control punitivo al incluir como eventuales sujetos de control a todos quienes se vean involucrados en el traslado de mujeres prostitutas» (Abadía, 2012, p. 116). Lo inverso también ocurre quizá por la indeterminación del tipo penal. Hay casos - cuya frecuencia tampoco se determina, evidenciando la necesidad de más estudios cuantitativos - donde los fiscales se abstienen de imputar cargos porque, si bien logran acreditar la explotación sexual, increíblemente sugieren que no existe una finalidad de explotación debido al supuesto «consentimiento de la víctima». Queda patente la tensión entre la criminalización y descriminalización del comercio sexual, al no haber «claridad sobre cuándo una mujer que ejerce la prostitución va a resultar victimizada en el ámbito del discurso de la trata de personas o cuándo va a ser tomada como "una simple prostituta» víctima de un proxeneta» (Abadía, 2012, p. 116).

Nuestra investigación tiene algunos antecedentes en Perú. Está el trabajo de Jabiles (2017) donde se comprueba, en línea con los estudios antes citados, que muchos fiscales priorizan «casos emblemáticos». Casos donde las víctimas muestran atributos que el autor acierta en denominar «ideales»; en otras palabras, atributos accesibles de comprobar toda vez que son compatibles con el tipo penal de trata en el Código Penal peruano. Así, la víctima ideal es quien generalmente ha sido sujeto de explotación sexual, captada por una falsa oferta de trabajo, inocente (es decir, ajena a «comportamientos dudosos»), menor de edad, privada de libertad, sometida, sin posibilidad de escapatoria y vulnerable, pasiva y sin capacidad de agencia. Las personas que vivifican estos rasgos son foco de control penal. Jabiles (2017, p. 24) logra exponer «una aplicación selectiva de la ley penal que responde a criterios de idealización y jerarquización", cuyas consecuencias son la exclusión de un número indeterminado de víctimas difíciles de corresponder con el tipo penal de trata y, por otro lado, «el riesgo de la revictimización y objetivación de las víctimas en el sistema de justicia a partir de la dependencia probatoria en el testimonio de 
la víctima». Efecto inverso a lo antes documentado: si en otros países se detecta la ampliación de la categoría "trata», aquí esta se restringe a personas de atributos específicos. En otras palabras, un acotamiento de la respuesta penal, del espectro de la criminalización secundaria (Zaffaroni, 2002).

Otros trabajos discuten sobre dogmática penal y problemas de interpretación judicial. Aquí destaca la valoración crítica de Montoya (2016) sobre la actuación de las salas penales de la Corte Suprema en Perú. El autor llama atención sobre el hecho de que algunas resoluciones recurren a plantear la pertinencia de los «medios comisivos» en casos de menor de edad, cuando ni el Protocolo de Palermo ni el Código Penal peruano lo requieren. Lo mismo en materia de consentimiento. Si el razonamiento jurídico es el correcto, el aprovechamiento de la prostitución de menores califica como trata de personas, volviéndose irrelevante averiguar — como hace la Corte Suprema en los fallos analizados por Montoya (2016) - sobre la capacidad de agencia de los menores. Lo documentado por el autor constituye un comportamiento procesal similar al documentado en otros contextos nacionales.

Por último, en trabajos orientados al mundo de la sociedad civil, la organización Capital Humano Social y Alternativo ha publicado informes con evidencia abundante sobre el Perú. Uno del año 2011 (titulado el Proceso penal en el delito de trata de personas) muestra que no se respetó la identidad de la víctima en muchos procesos penales, y que las medidas de protección fueron ineficaces, quedando aquellas a merced de amenazas por parte de tratantes (Capital Humano y Social Alternativo, 2011). Los fiscales entrevistados por dicha organización manifestaron similares dificultades a las documentadas en Colombia para distinguir entre trata y prostitución. Lo anterior se agravaría en escenarios rurales donde la geografía y la debilidad institucional del Estado impone un mayor desafío para la administración de justicia en comparación a zonas urbanas (Mujica y Cavagnoud, 2011).

\section{Contexto Legal y SOCial}

La consigna de combatir la trata de personas, en sintonía con las reformas derivadas de la Convención contra la Delincuencia Organizada Transnacional (en adelante, Protocolo de Palermo), es un hecho de trascendencia jurídica y social. En el Perú, desde 2003 cuando entró en vigor la citada convención, cerca de 43 dispositivos legales han sido adoptados en la materia (Montoya, 2012). Es importante considerar, para efectos de nuestro análisis, los siguientes elementos: (i) el tipo penal que tipifica el delito de trata en el Código Penal peruano y la ley que lo perfecciona (Sistema Peruano de Información Jurídica [SPIJ], 2007); (ii) el Plan Nacional de Acción contra la Trata dePersonas 201 (Ministerio del Interior [Mininter], 2017); (iii) la creación de fiscalías especializadas y (iv) también aartículos del Código Procesal Penal. 
(i) La ley 28950 de 16 de enero de 2007 tipificó el delito de trata de personas en la legislación penal. Dicha tipificación inicial fue objeto de críticas al no ser «claras» las pautas para acreditar el delito en diversos casos. La ley 30251, de 30 de setiembre de $2014^{10}$, simplificó los términos para acreditar trata en casos de menores de edad. Bajo la nueva formulación — reiteramos en casos de menores de edad- se prescindía de los llamados «medios comisivos», bastando acreditar la concurrencia de una conducta típica y de los fines de explotación prescritos en la norma (ver Montoya, 2012 para un análisis detallado).

(ii) El Plan Nacional contra la Trata de Personas 2017-2021 es la propuesta del Estado para combatir la trata. Un documento político ambicioso, que propone un repertorio de objetivos, metas eindicadores de persecución penal, prevención, protección de víctimas, etc. En el ámbito persecutorio, se debe tener en cuenta que los operativos de interdicción son la acción medular del Estado: la "punta de lanza» para detener imputados y "rescatar» víctimas. Un atributo clave para entender la actuación fiscal es que, no obstante ser muy ambicioso, el citado plan carece de presupuesto ad hoc para ser ejecutado (Mininter, 2017, p.61).

(iii) La apertura de fiscalías especializadas es un hecho muy importante porque, desde entonces, existen grupos de fiscales dedicados exclusivamente a investigar la trata de personas. Con ello, la persecución penal y el rescate de víctimas de trata de personas se vuelven prácticas sistemáticas del sistema penal en Madre de Dios.

(iv) El Código Procesal Penal establece que el Ministerio Público es el titular de la acción penal y que los fiscales son la autoridad de la investigación penal, teniendo a la Policía Nacional del Perú y al Instituto de Medicina Legal como aliados. Los fiscales ocupan una posición de autoridad, que se fortalece con el prestigio fruto de investigaciones exitosas (SPIJ, 2004). Conviene añadir que todos los departamentos del país cuentan con una junta de fiscales. En Madre de Dios, por acuerdo de junta (documento al que no obtuvimos acceso), los fiscales ejecutan operativos antitrata todas las semanas bajo los objetivos señalados en el punto ii.

Se desprende que practicar operativos semanales es la tarea primordial de los fiscales. Dentro de este grupo existiría consenso en la prioridad a los casos de menores.

10 Para efectos de nuestro análisis, tomamos la definición de trata de personas del artículo 153 Código Penal, que reproduce los mismos términos de la definición universal del Protocolo de Palermo de la Organización de las Naciones Unidas: «[E]l que mediante violencia, amenaza u otras formas de coacción, privación de la libertad, fraude, engaño, abuso de poder o de una situación de vulnerabilidad [...] capta, transporta, traslada, acoge, recibe o retiene a otro, en el territorio de la República o para su salida o entrada del país con fines de explotación, es reprimido con pena privativa de libertad no menor de ocho ni mayor de quince años». Respecto de la trata de menores, el inciso 3 del citado artículo establece lo siguiente: «La captación, transporte, traslado, acogida, recepción o retención de niño, niña o adolescente con fines de explotación se considera trata de personas incluso cuando no se recurra a ninguno de los medios previstos en el inciso 1 (SPIJ, 2007). 
Si bien para ellos estos casos tendrían una mayor connotación de gravedad, coinciden con que son más sencillos de acreditar por la ley vigente ${ }^{11}$. También quedan evidenciadas las restricciones presupuestales. Madre de Dios tuvo un presupuesto de S/ 13,068,150 (USD 3867 460,71) para investigaciones fiscales en 2017 (Ministerio de Economía y Finanzas, 2017). Sin embargo, estos recursos se distribuyen para gestionar todo tipo de casos judiciales. ¿Los fiscales evitan investigacionescomplejas? ¿Territorios y casos que requieren reiteradas diligencias? Es probable, aunque sabemos de sistemas penales ricos en recursos pero de respuestas selectivas similares a las documentadas aquí (Farrell et al., 2014). Lo importante es tener en mente que condiciones jurídico-penales y económicas específicas puedes condicionar seriamente la labor fiscal.

La minería aurífera y la trata conforman un binomio en Madre de Dios ${ }^{12}$. Es decir, redes de trata suministran fuerza de trabajo a campamentos mineros y negocios informales que allí operan, tales como bares, restaurantes y hostales (Mujica, 2014). La minería en esta región no es reciente sino data del siglo XX, un proceso que García Morcillo (1982) documenta con precisión. Dicha actividad reemplazó en su momento a la extracción de caucho, atrayendo masivas corrientes migratorias desde zonas altoandinas, un proceso facilitado por los proyectos de infraestructura vial que el Estado desarrolló durante el siglo XX. Sin embargo, es verdad que el territorio minero se expande de forma inédita en las dos últimas décadas ${ }^{13}$. Ocupaba menos de $10 \mathrm{mil}$ hectáreas en 1999, pero en 2012 ya excedía las 50 mil (Asner, Llactayo, Tupayachi y Luna, 2013). Creció tanto la minería que hoy penetra las reservas de Manu y Tambopata (World Wildlife Fund, 2017), donde habitan pueblos indígenas y ecosistemas únicos en biodiversidad. Por Madre de Dios atraviesa la ruta interoceánica Perú-Brasil,

\footnotetext{
11 Sin embargo, como vimos antes, la selectividad penal tiene lugar en contextos nacionales donde no existe semejante estándar probatorio.

12 Madre de Dios tiene 137316 habitantes (Perú tiene un total de 31 millones 237 mil 385). Es el departamento peruano menos poblado de Perú, pero que ha tenido la mayor tasa de crecimiento poblacional y el mayor saldo migratorio neto, cercanos a 3,4 y 14\%, respectivamente (Yamada, 2012, p. 100). El $31 \%$ de su población se dedica a actividades extractivas (Instituto Nacional de Estadística e Informática [INEI], 2012, p. 387). El 85\% de la economía informal (INEI, 2014, p. 96). La minería representa el $43 \%$ del valor agregado bruto departamental (INEI, 2012, p. 391). Las reservas de oro probables y probadas son de 155 y 138 miles de onzas, respectivamente (INEI, 2012, p. 390). Madre de Dios es uno de los departamentos con menor pobreza monetaria del país, con tasas oscilantes entre 2,1\% y 4,8\% (INEI, 2018, p. 46). Por último, en 2015 la tasa de homicidios departamental fue de 18,9 por cada 100 mil habitantes, una de las más altas del país (INEI, 2016, p. 14).

13 Según datos del Ministerio del Ambiente (Minam, 2017), entre 2001 y 2016, se perdieron 162573 hectáreas de bosque húmedo amazónico. Desde 2010, la pérdida de bosques anuales supera las 10 mil hectáreas en todos los años. Asimismo, el Informe Técnico 00008-2016-INDECI/11.0 señala que «distintos grupos poblacionales de Madre de Dios presentan niveles de mercurio en su organismo por encima de los límites máximos permisibles» (Presidencia de la República del Perú, 2016).
} 
única conexión vial entre estos dos países y cuya construcción a inicios de 2000, dicen algunos, facilitó la apertura de minas (Novak, 2009).

Existen tres núcleos mineros que nos conciernen, básicamente porque son objeto de intervenciones regulares del Ministerio Público. Estos se ubican en la margen izquierda del río Tambopata (km 109 de la Interoceánica); en ambas márgenes del río Malinowski, que está al sur del km 109 de la mencionada ruta; y en las inmediaciones del distrito de Huepetuhe. Entre los km 98 y 108 de la carretera Interoceánica está La Pampa, suerte de punto medio entre estas zonas mineras, y que para muchos simboliza el corazón de la trata de personas. Se trata de una pampa, en efecto, un territorio baldío cercano a la carretera, donde abundan negocios de comidas, bares, ferreterías y hospedajes ${ }^{14}$. La descripción, sin embargo, es unánime y generalizada: en este territorio la tierra se ha vuelto yerma y se observan cráteres por doquier. Son perforaciones llenas de lodo, donde apenas uno que otro solitario árbol se resiste a caer. El sonido de las máquinas extrayendo oro es permanente. Y aunque la tierra y los ríos están contaminados por mercurio, las personas trabajan y viven allí dedicados a la minería y negocios conexos. Se desconoce la cantidad de víctimas de trata de personas en este contexto (Mujica, 2014).

\section{Desafíos EN LA GESTIÓN DE OPERATIVOS CONTRA LA TRATA DE PERSONAS}

La primera tarea es reunir al personal de confianza, generalmente policías amigos que conocen la ruta, ofrecen resguardo y saben trabajar la escena del crimen (los fiscales muchas veces costean, con sus propios recursos, los gastos de movilidad y de alimentación del personal policial). Se suman también funcionarios del Instituto de Medicina Legal, del Ministerio de la Mujer para dar asistencia psicológica a las víctimas, y defensores públicos del Ministerio de Justicia. Los fiscales mismos alquilan vehículos, por lo general camionetas, motocicletas y una van. Las provisiones para la jornada incluyen, además de alimentos, combustible y cuerdas para sortear eventuales inundaciones. Obviamente en el camino se ha reunido ya información de inteligencia, que proviene de personal policial, funcionarios de salud y trabajadores informales a quienes se les paga como informantes. La Fiscalía Provincial Especializada en Delitos de Trata de Personas consta de cuatro fiscales y dos administrativos. Son funcionarios con tareas ad hoc, y competencia en los $85000 \mathrm{~km}^{2}$ de superficie del departamento.

La historia de los operativos en la región es interesante. No existían intervenciones propiamente focalizadas contra la trata antes de 2014. Por aquellos tiempos,

14 Entre 2009 y 2014, la cantidad de casos por trata de personas en Madre de Dios fue de 227. Anualmente, la cifra ha oscilado entre los 15 y 54 casos (Ministerio de Justicia, 2017). 
durante la gestión de Daniel Urresti como ministro del Interior, el Estado hacía megaoperativos. Estas intervenciones implicaban un despliegue masivo de personal policial y fiscal, con el objeto de detener imputados por delitos ambientales. Participaban también periodistas, motivados de capturar el momento preciso en que la policía destruía la maquinaria utilizada en minería. Lo concerniente a la trata era un poco secundario en este procedimiento. A decir de nuestros informantes, lo que estas intervenciones tenían de espectaculares no lo tenían de efectivas. Muchos megaoperativos eran anticipados. Involucraban a tanto personal que solía filtrarse información sobre «donde se iba a golpear». Desde 2014, la Fiscalía Provincial Especializada en Delitos de Trata de Personas inicia operativos ad hoc contra la trata. Lección aprendida: no más megaoperativos, sino intervenciones acotadas lideradas por el Ministerio Público, en pequeños grupos y guardando reserva.

Cuando viene infinidad de personal judicial con helicóptero, logística y todo, cuando llegamos al lugar ya no encontramos nada. Todas las víctimas han sido llevadas a otro lugar. Y preguntamos ¿qué ha pasado? Ya nos avisaron desde ayer, desde las 11 a.m., de que iban a venir ustedes. Es por eso que sus bares se han llevado sus cosas. A las chicas las han llevado a otro lugar. De tal manera que trabajar así a nivel macro. (Fiscal 3, Puerto Maldonado, 2016).

Con todo, riesgo de filtraciones persiste y es difícil de anticipar. Este riesgo aumenta considerablemente cuando los operativos son en zonas distantes de Puerto Maldonado (la capital de Madre de Dios). En consecuencia, los fiscales tienden a restringir la respuesta penal a territorios accesibles. La versión unánime es que estas filtraciones provienen de la PNP. De hecho, informantes en esta entidad admiten dicha responsabilidad. Reconocen que los contactos en territorios mineros. Pero argumentan que esas relaciones informales les facilitan acceder a dichos espacios, alquilar vehículos y hospedajes seguros. El jefe policial al mando adjudica las filtraciones a «malos policía». Si bien la PNP se encarga del patrullaje y entra poco a los campamentos mineros, los trabajadores mineros salen frecuentemente a las zonas urbanas a abastecerse. Es allí cuando hacen contactos informales con la PNP, a decir de los entrevistados.

Cuando trabajamos desde arriba, cuando queremos organizar cualquier operativo, se comunica al general o al jefe de la DIVINCRI, y ahí es donde se nos va la información. Es decir, se nos filtra la información. Supongamos: tenemos información de que en determinado local existen trabajando menores de edad, hemos intentado hacer el operativo a nivel macro, por seguridad sobre todo, y ocurre de que una hora antes en esos locales se enteraban que íbamos a intervenir y ya tomaban medidas para evadir. Digamos que el trabajo se iba al agua. (Fiscal2, Puerto Maldonado, 2016). 
El trabajo de campo permitió identificar dos rutas adicionales de filtración, una proveniente de personal administrativo de las agencias de control del delito - cuyas familias viven o trabajan en territorio minero-y otra que provendría de funcionarios del Registro Nacional de Identificación y Estado Civil (Reniec). Funcionarios de esta entidad, según muchos entrevistados, facilitan documentados de identidad adulteradores a menores de edad en territorios mineros. No fue posible encontrar registro de denuncias por estos hechos, ni de parte del Ministerio Público o de la PNP. Estaríamos pues ante un signo problemático de falta autonomía estatal (Soifer y vom Hau, 2008), que desvía la dirección del sistema de justicia penal.

Además de las filtraciones, la geografía de la zona es un desafío mayor para los fiscales. Los campamentos próximos al río Tambopata están a $140 \mathrm{~km}$ de Puerto Maldonado. Los del río Malinowski están a $160 \mathrm{~km}$. Los del distrito de Huepetuhe a $250 \mathrm{~km}$ (Google Earth, 2018). Es verdad que la carretera Interoceánica conecta con la entrada a estos territorios, pero atravesarlos es imposible con automóviles. Los fiscales necesitan motocicletas para surcar los caminos de trocha. No extraña verlos a bordo de pequeñas balsas cruzando riachuelos. Los funcionarios consideran peligroso incursionar en zonas mineras sin resguardo policial. Son condiciones que llevan a que muchos fiscales prefieran intervenir campamentos de más fácil acceso.

En Huepetuhe no tenemos división médico legista, pese a que existe la plaza. Pero como no están bien remunerados, los médicos no se van a esa zona alejada a trabajar. Igual los psicólogos y ya han renunciado varios de ellos, entonces tiene que venir la víctima sí o sí acá [a Puerto Maldonado]. Ahora, a esas 6 horas [de diligencias], hay que sumarle otro tiempo para dejar al detenido y los actuados hasta Huepetuhe. Entonces son prácticamente 12 horas que te resta de investigación, y ahí te juegas contra el tiempo. Y ahí pero en caso de Delta. Ahí sí es trágico Delta, que todavía está a dos horas hacia adentro de Huepetuhe. Entonces ahí te limita mucho. (Fiscal 3, Puerto Maldonado, 2016).

Dicho esto, la condicionante esencial de los operativos es presupuestal, generando una respuesta adaptativa paradigmáticas: los fiscales suelen financiar los operativos con sus salarios. Cada uno de los cuatro fiscales integrantes de la Fiscalía Provincial Especializada en Delitos de Trata de Personas invierte cerca de S/ 800 al mes por operativo (USD 239,38 aproximadamente). Cuatro operativos al mes (uno semanal) equivalen a S/ 2400 de inversión (USD 718,15). Es llamativo el contraste entre las ambiciones de la política criminal y la realidad de los fiscales financiando los operativos de esa manera: con sus ingresos. Por supuesto que el uso de dineros propios desalienta las incursiones en zonas distantes. ¿¿Se imaginan qué puede significar para un fiscal que lo invertido no derive en detenciones o en rescate de víctimas, por ejemplo como consecuencia de las mencionadas filtraciones? Lo sienten como una inversión perdida. Estos desafíos presupuestales llevan a los 
fiscales a racionalizar la respuesta penal, discriminando territorios en función del acceso, y los casos en función de la complejidad.

Cada uno tiene que correr con sus gastos. Al inicio, yo me acuerdo la gravedad de los casos en Huepetuhe y Delta. Nos llevamos a los policías de más escasos ingresos económicos. Teníamos que pagarles. Teníamos la esperanza que la institución nos iba a reponer los viáticos, pero hasta la fecha ya me gaste más de 800 soles, que aún no me repone la institución. Perobueno pues, ¿qué nos queda? Solamente la gratificación del trabajo que tenemos. (Fiscal 1, Puerto Maldonado).

Con los operativos viene adjunto el reto de gestionar los traslados de las víctimas, dado el limitado número de vehículos. Los fiscales deben discriminar a quién trasladar primero. Los casos de menores tienen concitan mayor urgencia, por la gravedad in trínseca de los mismos. Desde las zonas mineras hasta Puerto Maldonado, las víctimas viajan unas tres horas para llegar a las oficinas del Instituto de Medicina Legal. Después se las deriva a la ciudad de Mazuco, a 167,8 km, donde están los albergues. En ocasiones, cuya frecuencia no pudimos determinar, la víctima y el imputado comparten el mismo vehículo.

El otro problema es que el albergue es para 18, 18 personas, y actualmente siguen haciendo operativos casi interdiario, y un día llevaron como a 6 víctimas que eran menores de edad. Cuando son mayores de edad, bueno, no se les obliga. Y bueno dicen «me retiro». No se les puede obligar, pero en el caso de los menores, nosotros síle damos la custodia porque de alguna manera disponemos (ininteligible) por abandono. (Trabajadora social, Puerto Maldonado, 2016).

En verdad, se atienden a mujeres y menores hasta los 18 años. Tenemos un problema que actualmente están trayendo casos de explotación laboral, y son niños y adolescentes. En el caso de varones no contamos con CAR [Centro de Atención Residencial], no contamos con CAR y es una preocupación porque se muestra muchas veces el abandono total de sus propios hermanos que ya son mayores. Que han pasado la mayoría de edad y ellos mismos los traen a sus hermanos, ya sea trabajando en los bares o trabajando en la minería. (Psicóloga, Puerto Maldonado, 2016).

Un criterio de cupos define el acceso a los albergues. El albergue estatal tiene capacidad para 18 personas. Otros administrados por organizaciones de la sociedad civil tienen también una capacidad limitada. Los fiscales narran situaciones insólitas, como la necesidad de hospedar a las víctimas en hoteles o casas de familiares. El Ministerio de la Mujer asignó en 2017 S/ 1487864 para atender a personas en estado de abandono (USD 440 326,71); sin embargo, los albergues son dispositivos noespecializados puesto que reciben todo tipo de víctimas. Como vemos hasta aquí, organizar operativos demanda que el fiscal ejecute un repertorio de habilidades 
administrativas, logísticas y, por supuesto, jurídicas: reunir a personal de confianza, alquilar vehículos, comprar provisiones, cautelar la cadena de custodia probatoria, evitar filtraciones, cuidar los plazos y proteger a las víctimas.

\section{Desafíos PARA JUdicIALIZAR los CASOS IDENTIFICADOS}

El obstáculo principal en materia procesal es acreditar el delito de trata cuando la víctima es una mujer adulta. Los fiscales reiteran la dificultad de obtener testimonios con valor probatorio en estos casos, una situación documentada ampliamente en otros contextos nacionales (Matos et al., 2017; Reid, 2013). En particular es difícil probar los medios comisivos (que la víctima fue objeto de violencia o de algún abuso de poder). Se dificulta corroborar tanto la victimización y, en consecuencia, también la responsabilidad penal. La explotación a que estuvieron sometidas inhibiría a muchas víctimas a declarar. Puede incluso suceder que una persona haya sido tratada en algún momento de su biografía, y que — como consecuencia del proceso de explotación - hoy no se perciba más como víctima. El reto es mayor aún dadas las complicaciones de realizar investigaciones judiciales en zonas distantes y consideradas peligrosas:

En sí cuando hablamos de trata de personas no se discrimina. No es que tengamos prioridad rescatar a menores. La prioridad es rescatar víctimas, cualquiera sea su edad. Pero sí hay que reconocer que la víctima mayor de edad juega siempre en contra de la investigación. Te decía que juega en contra de la investigación porque cuando son mayores de edad ellas tienen la libertad de poder consentir ciertos actos. Por ejemplo, muchas de las señoritas dicen «no, yo estoy aquí con mi consentimiento», «no hago nada», «yo estoy acá porque quiero», «no conozco a nadie», «nadie me controla», «yo mismo me siento con el cliente», «yo mismo me anoto», «yo mismo administro", "todos administramos». [...] En el caso de menores de edad, solo se requiere [acreditar] que haya conducta y fines. No se requiere que haya medios. En el caso de mayores de edad, si es que no hay engaño, si es que no hay los medios, se vuelve prácticamente ya no punible. (Fiscal 2, Lima, 2017).

Los lectores deben poner en perspectiva que los fiscales investigan en asociación con funcionarios de diversas agencias estatales, entidades cuyos recursos a veces son aún más escasos en comparación al Ministerio Público. Dicha cuestión relacional es poco comentada en la literatura especializada. Así, la Policía Nacional del Perú y el Instituto de Medicina Legal carecen de herramientas para resolver casos complejos, mientras que la PNP acusa falta de agentes encubiertos y teléfonos satelitales. Los primeros sirven para obtener material incriminatorio sobre participantes en redes de trata y sobre la situación de las víctimas. Los teléfonos satelitales sirven, entre otras cosas, para consultar en el sistema de Reniec pues — recordemos- existen cédulas 
de identidad falsificadas en los territorios mineros. Por otro lado, los médicos legistas insisten en que las condiciones de trabajo son deficientes:

No hay presupuesto para designar un agente encubierto, [que] se pueda quedar en un hostal o pueda hacer seguimiento. A este agente encubierto hay que darle sus viáticos, desayuno, almuerzo y comida para que permanezca al menos 3 días y haga un buen trabajo. Pero no se cuenta con eso. También nos hablan de la videovigilancia. Para la videovigilancia igual tenemos que tener cámaras especiales. Incluso cámaras que puedan grabar de noche. No tenemospresupuesto para eso. Entonces, por ahí nos vemos muy limitados dentro de los conceptos y herramientas para luchar contra el delito de trata de personas. (Fiscal, Puerto Maldonado, 2016).

Por ejemplo, yo le digo así dentro de lo que son delitos contra la libertad sexual o trata, lo que nunca hemos tenido es un colposcopio. Es un aparato que permite ver el interior de la vagina, parte del cuello del útero, o ver con mucha más nitidez el área genital propiamente. Entonces eso nunca hemos tenido. (Médico Legista 1. Puerto Maldonado, 2016).

Se infiere que el soporte médico-policial permitiría conseguir medios probatorios auxiliares al testimonio. El proceso penal, en este contexto, depende mucho del valor de la prueba testimonial. Dicho atributo fue también documentado en una investigación anterior que hice sobre feminicidios en el Perú (Tuesta y Mujica, 2015). Es verdad que el fiscal puede recurrir a pruebas indiciarias y emplear todo su acervo de conocimiento jurídico. Sin embargo, existe el riesgo de que el juez de investigación preparatoria rechace la acusación. Estos problemas se reducen de forma considerable en casos de menores, porque el tipo penal exime de tener que corroborar los famosos «medios comisivos». Hay también una cuestión de «interdependencia funcional». Los fiscales necesitan el diagnóstico del Instituto de Medicina Legal. El problema con dicha unidad es que atiende todo tipo de delitos. La sobrecarga procesal es extraordinaria, lo mismo que las deficiencias materiales. El fiscal sabe que debe racionalizar la cantidad de víctimas puestas a disposición de Medicina Legal, con lo cual termina priorizan casos que tomarían un menor tiempo y que tendrían mayor probabilidad dejudicialización.

Cuando generalmente vamos a La Pampa, que es uno de los lugares donde hay más incidencia de trata de personas, regresamos no con 2 o 3 víctimas: regresamos con 6 u 8 víctimas. Ahora, ¿qué pasa? Cuando tenemos detenidos, la ley nos dice: «Ministerio Público, tienes 24 horas para ver si formalizas la investigación o si dejas en libertad a tu detenida” ¿Y qué es lo que ocurre? Para salir de La Pampa te demora de una a dos horas. [...] Desde kilómetro 108 te demora dos horas y media aproximadamente para venir a la ciudad [de Puerto Maldonado]. De 24 horas se va restando 4 horas. Ahora, llegas acá y, si llegas de noche, no tenemos psicólogos disponibles. Y si es que hay psicólogos, hay uno que te dice: «yo no puedo evaluar a más 
4 personas». ¿Por qué? No es posible en sus manuales ni tampoco aceptable que hagan más pericias. (Fiscal 4, Puerto Maldonado, 2016).

Por ejemplo acá en la zona, encerrados en un consultorio sin ventilador, estar en una entrevista por ejemplo 50 minutos, que son en vano, suda el psicólogo, suda la entrevistada. Eso produce que haya desatención, desconcentración, se siente aturdida. Es igual al psicólogo. Se trabaja en la humedad. O sea sinceramente uno tiene que abrir la puerta y abrir la puerta y a veces hay sonidos, niños que pasan, y uno se desconcentra y ya. Y según nuestra guía tiene que haber privacidad, tiene que haber facilidades en cuanto al ambiente, tiene que ser un momento ideal, silencioso, pero no, no sé, así es... (Psicólogo clínico, IMLCF-Puerto Maldonado, 2016).

Si bien la capacidad presupuestal condiciona el desarrollo de la acción penal, la evidencia de campo permite matizar un poco las cosas. La desigualdad de recursos entre las agencias sería lo que verdaderamente condiciona y favorece la selectividad del sistema penal. La Fiscalía Provincial Especializada en Delitos de Trata de Personas tiene recursos modestos, pero otras agencias tienen aún menos recursos y carecende funciones focalizadas en la judicialización del delito en cuestión.

\section{TÉCNICAS DE COMPENSACIÓN}

La evidencia de campo muestra que los fiscales disponen de sus salarios para financiar los operativos y, así, compensar las limitaciones presupuestales. La pregunta es ¿por qué lo hacen y qué los motiva a invertir de sus salarios? Partiré señalando que los citados funcionarios expresan una fuerte pertenencia a la misión y a los valores del Ministerio Público. Esto puede responder a la posición jerárquica que ocupan en la institución. Recordemos que el Código Procesal Penal consagra al Ministerio Público como titular de la acción penal, cuestión que los fiscales interpretan como sinónimo de estatus. En las entrevistas, expresan orgullo de ser «fiscales especializados» en una materia. Recordemos, por otro lado, que el mérito de muchas intervenciones se individualiza en el fiscal. Cosa contraria en el caso de policías y médicos, donde el mérito se distribuye grupalmente. Es insólito que las agencias feliciten a un médico o a un policía por el éxito de un operativo o de una pericia médica. Común es que se felicite al grupo. Los policías, por ejemplo, tienen salarios modestos y la mayoría tienen rango de suboficial. Cosa no menor: los fiscales son invitados a conferencias, pasantías, capacitaciones, en una mayor frecuencia que los colegas de otras entidades:

A todos mis compañeros les gusta el trabajo de la fiscalía. Es gratificante por ejemplo el personal que está ahorita en trata de personas. Todo es de confianza. A nivel nacional son fiscalías nuevas. Y el Consejo Nacional de la Magistratura aún no ha convocado la plaza para titulares. Entonces, como son nuevas plazas, el Presidente de la Junta de Fiscales, a través de Fiscal de la Nación, ha escogido a los que 
mejor se desempeñarían en la labor de lucha contra la trata de personas. Eso hace que todos los compañeros magistrados, tanto fiscal provincial y adjuntos, tengan habilidades distintas. Eso de alguna manera [hace] que suplamos o superemos los obstáculos que ahora tenemos. (Fiscal 1, Puerto Maldonado, 2016).

Así como la desigualdad de recursos condiciona la respuesta penal, se puede sugerir lo mismo sobre la desigualdad de incentivos y reconocimiento entre los grupos ocupacionales. Los incentivos mencionados -especialización, expectativas de ascenso, estatus, reconocimiento, ingresos - favorecerían que los fiscales desarrollen semejante identificación con la misión y valores institucionales. Cabe especular con que dicho sentido de pertenencia contribuye a que sigan trabajando pese a las adversidades. ¿Cómo relacionar esta consideración con el desarrollo de una respuesta penal selectiva? Conviene recordar que la acumulación de operativos exitosos aumenta la probabilidad de que el fiscal ascienda en la jerarquía institucional. Cuando el fiscal invierte parte de sus ingresos, está apostando por una línea de carrera. Hemos visto que los operativos que priorizan el rescate de niños y niñas se traducen más fácilmente en indicadores de éxito, fortaleciendo las expectativas de ascenso y la imagen pública del fiscal en la institución.

Como sin querer queriendo, me especializo en el tema. De poco a poco me voy especializando. Y bueno, ahora quiero decir que al menos estando dentro de la Fiscalía en la especialidad tengo suficiente experiencia para discutir algo sobre el tipo penal de trata de personas: cómo se desarrolla una investigación en la trata de personas, cómo recabar los indicios, las evidencias necesarias para en un juicio próximo tener éxito. [...] Y es bastante, es un, yo diría, que es un compromiso no solamente con la institución, sino con la familia y con la sociedad. (Fiscal 1, Puerto Maldonado).

Se observa un contraste notable entre el discurso de los fiscales y del personal del Instituto de Medicina Legal. La narrativa de médicos y psiquiatras evidencian descontento por las condiciones de trabajo. No es casualidad —al leer estos testimonios - que muchos refieran al Instituto de Medicina Legal como el «eslabón más débil». En un artículo anterior advertíamos que este tipo de expresiones no permiten algo concluyente sobre el estado material de las instituciones (Tuesta y Mujica, 2015). Sin embargo, estas expresiones son indicios relevantes sobre el clima emocional dominante en un grupo profesional. Asociarlo con deficiencias en el servicio de atención a víctimas, con una mayor revictimización, es tarea pendiente de futuros estudios.

Si usted va al Ministerio Público, tiene computadoras, tiene aire acondicionado. Como le digo respecto de sus capacitaciones, a cada rato dan. Acá ve usted este ventilador: lo estoy trayendo de arriba. Aquí tenemos un cementerio de ventiladores, no hay aire acondicionado, las computadoras están mal. Yo ando como un 
psicólogo satélite: donde hay oficina voy, donde hay oficina, así yo voy y estoy así. Pido un ITS, no me lo dan, pero sí priorizan para los que quieren salir. Entonces todo eso hace que uno no se identifique con el Ministerio Público. Y por eso te digo: ni capacitaciones, ni logística. No se hace sentir. No nos hacen sentir como [parte del Ministerio Público]. (Psicólogo clínico 3, Puerto Maldonado).

Las entrevistas sugieren, por último, aspectos importantes sobre los límites del poder punitivo. ¿A qué nos referimos? Los fiscales atraviesan por estos desafíos no sin construir una narrativa de sacrificios y sobre cómo llevan sus relaciones interpersonales. Se esmeran en comunicar una imagen pública, una imagen de sí mismos, como funcionarios abnegados y dispuestos a superar cualquier adversidad. Nos animamos a especular con que esta retórica fortalece la autoridad y legitimidad del fiscal en el sistema penal. Es razonable pensar, en ese sentido, que la acumulación de casos de menores de edad judicializados fortalece dicha representación. Obtener reconocimiento público como fiscales especializados, con una foja de servicios donde destacan casos sensibles, parece constituir un capital político y simbólico relevante.

Hay un colega quien recuerdo con mucho especial cariño. Es un colega muy bueno, con él me he cuajado, nos hemos forrado, nos hemos fajado, hemos trabajado de sol a sol los 2, con la finalidad de levantar esta fiscalía. Humanamente hacíamos lo posible porque la carga había sobrepasado. Entonces ese año renunciaron muchos. (Fiscal 3, Puerto Maldonado, 2016).

Mire, para mi buena suerte o no sé, para mi buena o mi mala suerte, en diciembre del año 2011 casi todos mi colegas eran de esta zona, de Puerto Maldonado, o tenían familia aquí en puerto Maldonado, en la capital del departamento. Eso motivó a que en fiestas navideńas y fiesta de ańo nuevo me entreguen a mí el turno de fiscal, bajo argumentos de que yo siendo de tan lejos no me iba a mover del lugar. Entonces tenía la obligación vamos a decir moral de quedarme, al margen que esté o no esté de turno. Pero ya, me entregaron el turno yo acepté de buena gana. Dije efectivamente yo no voy a moverme del lugar y estando ustedes tan cerca de sus familias y aprovechen, y es en diciembre, 25 de diciembre, 24 de diciembre del ańo 2011 cuando tengo mi primer caso de trata de personas: 2 adolescentes de 11, 12 años si mal no recuerdo, de zonas andinas del Cusco estaban siendo transportadas a esta localidad de La Pampa. Es ahí dondele pongo mayor atención al tema, veo lo complicado del tipo penal y bueno asumo otro reto más... (Fiscal 3, Puerto Maldonado, 2016).

Dentro de este registro subjetivo, los fiscales refieren constantemente a «otros generalizados». Por ejemplo, hablan sobre la relación que sostienen con las leyes que edifican el sistema penal, sobre las relaciones interactivas con colegas del Ministerio Público y de otras agencias, incluso con personas externas al sistema penal, que previamente discutimos al referir a la autonomía procesal: 
Yhay presencia [de minería aurífera] en la Reserva [Nacional de Tambopata]. En la reserva tenemos a ver, del kilómetro 107, 108, de la Carretera Interoceánica, esto es entre Puerto Maldonado Y Mazuco, en el medio de la carretera hay un ingreso. Por ese ingreso llegas en moto lineal hacia el «sector Chicles», hacia el sector «Los Megas», hacia el sector, hacia el sector «La Peña, hacia el sector «Malinoswki», antes de cruzar el rio grande, y esto queda ubicado más o menos a 2 horas y media a 3 en moto lineal [desde la Carretera Interoceánica. Hay gente que lo hace en menos, 2 horas, pero correr también en esa trocha es bastante peligroso. En un tramo, en un recorrido normal que hacemos nosotros, lo hacemos de 2 horas a 3. [...]. (Fiscal 2, Puerto Maldonado, 2016).

Pregunta: Imagino que no habrá suficientes guardabosques para...

No, definitivamente, y más todavía en ese sector no hay guardabosques, pasando el río Malinowski. Donde están los guardabosques, lógicamente ellos también están amenazados. Muchos han renunciado a consecuencia de las amenazas, pero nosotros seguimos allí. (Fiscal 1, Puerto Maldonado, 2016).

Estos discursos permiten sugerir que en los fiscales habita una representación sobre los campamentos mineros y sobre las víctimas adultas. Una representación que recuerda a Merton (2002) y su argumento sobre las profecías que se cumplen a sí mismas. Los fiscales califican los territorios mineros como «tierra de nadie». De forma parecida, suelen describir los casos de víctimas adultas como «casos perdidos». Ambas representaciones, ambos calificativos, fomentan dos creencias generalizadas. Que la única relación viable entre el Estado y estos territorios es a través del aparato policial y penal. De otro modo, ¿cómo te relacionas con «tierras de nadie? Mecanismos más positivos de control social quedarían — lo digo en condicional — relegados y fuera de discusión: el diálogo, la formalización, la prevención social, todo un repertorio de «recursos extra-penales» (Sozzo, 2000, p. 18). Asimismo, la etiqueta de «casos perdidos» anticipa que no valdría la pena destinar esfuerzos a la situación de víctimas adultas. Existe una relación entre representaciones y formas de práctica penal. Citando a Lacey (2009), dichas representaciones muestran el núcleo de una criminalización sustantiva (centrada en algunos casos emblemáticos); pero también sus límites: esa área gris de prácticas de comercio sexual cuya clasificación es incierta en el marco de la legislación penal basada en el estándar de las Naciones Unidas.

\section{Conclusiones}

Termino el artículo resaltando hallazgos que guardan similitud con otros escenarios de criminalización. Constato que los fiscales en Madre de Dios priorizan casos con indicadores de victimización más o menos claros, coincidentes con los enunciados del tipo penal. También que los fiscales priorizan casos que involucran a menores de edad, 
rasgo consistente con la teoría según la cual estos actores evitan la incertidumbre procesal. A decir de los fiscales, el perfeccionamiento del tipo penal en Perú facilitó la judicialización de la trata de menores; de lo cual, sin embargo, no podemos inferir que este cambio legal sea la causa del comportamiento selectivo aquí discutido. Por otro lado, la evidencia permite sugerir que el control penal habría crecido con la apertura de fiscalías focalizadas en trata de personas, rasgo coincidente con el estudio de Huff-Corzine, Sacra, Corzine y Rados (2017) sobre las mejoras ocurridas en Florida (EE.UU.) a partir de iniciativas similares. Otro hallazgo refiere a la sobredependencia en la prueba testimonial: la judicialización depende mucho de que la víctima aporte un testimonio incriminatorio, aspecto que los fiscales describen como un obstáculo procesal.

La literatura especializada coincide que la criminalización de la trata implica dos tipos de respuesta judicial, las mismas que parecen mutuamente excluyentes (no lo son a nuestro entender). Por un lado, la focalización del sistema en los reiterados casos de menores. Pero por otro, tenemos la expansión del rango de criminalización. $\mathrm{Al}$ no poder acreditar el delito de trata, muchos fiscales utilizan figuras conexas e inclusive criminalizan el trabajo sexual. No pudimos corroborar esto en Madre de Dios, más que el acotamiento de la respuesta penal a los casos «fáciles». Advertimos más bien que los fiscales construyen una narrativa de sacrificios marcados por varias limitaciones: para desplazarse a los territorios mineros, para trabajar la escena del crimen, para asistir a las víctimas. Los fiscales peruanos entrevistados carecen de suficientes herramientas para trabajar la escena del crimen, limitación que — hasta donde sabemos - no ha sido evidenciada en los estudios del Norte Global. Por último, una similitud con los trabajos citados en la revisión biográfica refiere a los desafíos para atender a las víctimas, dada la falta de espacios de acogida.

¿Es entonces la prioridad a casos accesibles signo de una conducta estable por parte de los fiscales? ¿Una inclinación a racionalmente evitar la incertidumbre, como propone la literatura? Nuestras entrevistas enseñan que los fiscales actúan motivados también por la misión institucional y el estatus que confiere la posición dentro de la jerarquía organizacional. Los fiscales — salvo que el relato implique alguna forma de cinismo- expresan identificación con los valores institucionales y un sentimiento de vocación debido a la posición jerárquica: se saben a sí mismos como titulares de la acción penal. Las entrevistas sugieren, en este sentido, que los casos de menores de edad provocan sentimientos (entre los fiscales) que dan el centro de ese núcleo de valores y sentido de pertenencia. Los actores manifiestan, cosa trascendental, que la acumulación de estos casos reditúa beneficios de carrera a largo plazo. Estos indicios deben tomarse aun con reserva debido al carácter exploratorio de nuestra indagación.

Lo dicho sobre la cultura organizacional y la estructura jerárquica induce a estudiar la actuación fiscal en relación con la capacidad que otros actores tienen para inter- 
venir dentro del sistema penal, línea de verdad poco explorada por la literatura. En ese sentido, un aporte de la investigación está en los testimonios del personal médico legista y de los trabajadores sociales, que permiten corroborar una importante desigualdad de recursos e incentivos entre las agencias y los funcionarios que las integran. Una conclusión es que estas desigualdades — y no tanto sencillamente la cantidad de recursos que dispone el sistema penal - condicionan el rango de criminalización; o sea, la cantidad de casos que el sistema penal es capaz de judicializar. Poniéndolo en términos relacionales, los fiscales son conscientes de que el personal del Instituto de Medicina Legal tiene carencias y consecuentes limitaciones para procesar muchos casos en simultáneo. Bajo esa premisa es que para un fiscal le resultaría preferiblecentrar la atención en casos fáciles de acreditar. Muchos funcionarios de esta institución, a diferencia de los fiscales, se sienten marginados al no gozar de comparables incentivos o beneficios de carrera ${ }^{15}$.

No quiero dejar de anotar la existencia de una creencia generalizada en los distintos grupos profesionales: que los casos de víctimas adultas son prácticamente casos perdidos. Como si hubiese predisposición a descartar esa clase de victimización, más aun cuando no se corresponde con los rasgos de una víctima ideal (Jabiles, 2017). Son casos probablemente mayoritarios y que se inscriben dentro del dominio general del comercio sexual. Se trata de un campo olvidado y desregulado en la Amazonía peruana (Mujica y Cavagnoud, 2011). No es exagerado especular alrededor de esta conjetura: que la criminalización de la trata focalizada en víctimas menores coincide con una tolerancia significativa a la trata de adultos, en un contexto de poca atención a políticas de regulación del comercio sexual y de la minería. El sistema penal —me permito avanzar en la hipótesis — reproduce dos regímenes de selectividad: uno hacia la trata de menores y uno distinto para la trata de adultos, el comercio sexual y la minería. No cuento con evidencia para trascender lo especulativo - y, por ejemplo, averiguar sobre la influencia de grupos de poder local—; pero creo este camino abre la oportunidad para pensar el lugar de la justicia penal en la pretensión estatal de regular las industrias extractivas informales en América del Sur.

Por último, un comentario epistemológico. Creo que es un camino acertado explorar la actuación fiscal en relación con lo que hacen —o dejan de hacer- otros grupos ocupacionales al interior del sistema penal. A menudo la literatura especializada toma la voz de fiscales en tanto permite informar sobre problemas o potenciales «mejoras», obviando que la criminalización es un resultado de acción colectiva. Estos otros grupos ocupacionales — tanto en sistemas de tradición civil y common law - tienen una participación clave en la judicialización. Los fiscales jamás actúan

\footnotetext{
15 Se puede especular con que el clima y las condiciones laborales del Instituto de Medicina Legal — descritas en las entrevistas - favorecen a la victimización secundaria.
} 
aisladamente. En ello en parte reside la aportación que procuro al introducción las nociones de prueba y experiencia social (Araujo y Martuccelli, 2010; Dubet, 2010; Martuccelli, 2007): hacer un inventario de los desafíos que los operadores de justicia atraviesan permite un análisis más plural, relacional y, por ende, complejo de sus comportamientos. Facilita discernir hasta qué punto la acción se explica por la voluntad de los actores o por lógicas que provienen de fuentes externas a ellos. Queda pendiente problematizar aún más (quizá en futuras entregas) los esquemas de elección racionales bajo los cuales se interpreta generalmente la actuación fiscal.

\section{REFERENCIAS BIBLIOGRÁFICAS}

Abadía, G. (2012). Usos y abusos del sistema penal. Su uso como forma de emancipación femenina: Un estudio de caso del delito de trata de personas en Colombia. Revista de Etudios Sociales, (42), 104-117. https://doi.org/10.7440/res42.2012.10

Albonetti, C. A. (1986). Criminality, prosecutorial screening, and uncertainty: Toward a theory of discretionary decision making in felony case processings. Criminology, 24(4), 623-644.https://doi.org/10.1111/j.1745-9125.1986.tb01505.x

Albonetti, C. A. (1987). Prosecutorial Discretion: The Effects of Uncertainty. Law \& Society Review, 21(2), 291.https://doi.org/10.2307/3053523

Araujo, K. y Martuccelli, D. (2010). La individuación y el trabajo de los individuos. Educacao e pesquisa, 36(spe), 77-91. https://doi.org/10.1590/S1517-97022010000400007

Asner, G. P., Llactayo, W., Tupayachi, R. y Luna, E. R. (2013). Elevated rates of gold mining in the Amazon revealed through high-resolution monitoring. Proceedings of the National Academy of Sciences, 110(46), 18454-18459. https://doi.org/10.1073/ pnas. 1318271110

Capital Humano y Social Alternativo (2011). El proceso penal peruano en el delito de trata de personas. 14 casos en Lima y Loreto. Recuperado de http://www. chsalternativo.org/ persecucion-del-delito-de-trata-de-personas/384-el-proceso-penal-peruano-enel-delito-de-trata-de-personas-14-casos-en-lima-y-loreto-1/ file

Comité de Ética de Investigación con Seres Humanos y Animales (2017). Protocolo de consentimiento informado para participantes. Recuperado de http://cdn02.pucp.education/ investigacion/2017/07/05170251/comEtica-manual-procedimientos_2017-07-05.pdf

Cortés-McPherson, D. (2019). Expansion of small-scale gold mining in Madre de Dios: 'Capital interests' and the emergence of a new elite of entrepreneurs in the Peruvian Amazon. The Extractive Industries and Society, 6(2), 382-389. https://doi. org/10.1016/j.exis.2019.01.002

Daich, D. y Varela, C. (2014). Entre el combate a la trata y la criminalización del trabajo sexual: Las formas de gobierno de la prostitución. Delito ysociedad, 23(38), 63-86. https://doi. org/10.14409/dys.v2i38.5554

Dubet, F. (2010). Sociología de la experiencia. Madrid: Editorial Complutense. 
Farrell, A. y Cronin, S. (2015). Policing Prostitution in an Era of Human Trafficking Enforcement. Crime, Law and Social Change, 64(4-5), 211-228. https://doi. org/10.1007/s10611-015-9588-0

Farrell, A. y Pfeffer, R. (2014). Policing Human Trafficking: Cultural Blinders and Organizational Barriers. The Annals of the American Academy of Political and Social Science, 653(1), 46-64. https://doi.org/10.1177/0002716213515835

Farrell, A., McDevitt, J. y Fahy, S. (2008). Understanding and improving law enforcement responses to human trafficking. Final report. Human Trafficking Data Collection and Reporting Center Research and Technical Reports, 1. https://doi.org/10.1037/ e457292008-001

Farrell, A., Owens, C. y McDevitt, J. (2014). New Laws but Few Cases: Understanding the Challenges to the Investigation and Prosecution of Human Trafficking Cases. Crime, Law and Social Change, 61(2), 139-168. https://doi.org/10.1007/ s10611-013-9442-1

Farrell, A., Pfeffer, R. y Bright, K. (2015). Police Perceptions of Human Trafficking. Journal of Crime and Justice, 38(3), 315-333. https://doi.org/10.1080/0735 648X.2014.995412

García Morcillo, J. (1982). Del caucho al oro: el proceso colonizador de Madre de Dios. Revista Española de Antropología Americana, 12, 255-271.

Google Earth (2018). Mapa de Ruta Interoceánica. Google.

Huff-Corzine, L., Sacra, S. A., Corzine, J. y Rados, R. (2017). Florida’s Task Force Approach to Combat Human Trafficking: An Analysis of County-Level Data. Police Practice and Research, 18(3), 245-258. https://doi.org/10.1080/15614263.2017.1291567

Instituto Nacional de Estadística e Informática (INEI) (2012). Perú: Principales indicadores departamentales 2007-2011. Recuperado de http://proyectos.inei.gob.pe/web/ biblioineipub/bancopub/Est/Lib1044/cuadros/ cap00.pdf

Instituto Nacional de Estadística e Informática (INEI) (2014). Producción y empleo en el Perú. Cuenta satélite de la economía informal 2007-2012. Recuperado de https:// www.inei.gob.pe/media/MenuRecursivo/publicaciones_digitales/Est/Lib1154/ libro.pdf

Instituto Nacional de Estadística e Informática (INEI) (2016). Homicidios en el Perú, contándolos uno a uno. 2011-2015. Recuperado de https:/www.inei.gob.pe/media/ MenuRecursivo/publicaciones_digitales/Est/ Lib1365/index.html

Instituto Nacional de Estadística e Informática(INEI) (2018). Evolución de la pobreza monetaria 2007-2017. Lima: INEI.

Jabiles, J. (2017). "Victimas ideales" y discursos victimológicos en la persecución de delito de trata de personas en la ciudad de Lima. Recuperado de http://tesis.pucp.edu.pe/ repositorio/bitstream/handle/123456789/9275/JABILES_ESKENAZI_JOEL_ VICTIMAS_IDEALES.pdf?sequence=1 8 isAllowed $=y$

Lacey, N. (2009). Historicising criminalisation: Conceptual and empirical issues. The Modern Law Review, 72(6), 936-960. https://doi.org/10.1111/j.1468-2230.2009.00775.x 
Mapp, S., Hornung, E., D’Almeida, M. y Juhnke, J. (2016). Local Law Enforcement Officers' Knowledge of Human Trafficking: Ability to Define, Identify, and Assist. Journal of Human Trafficking, 2(4), 329-342. https://doi.org/10.1080/23322705.2 016.1143764

Martuccelli, D. (2007). Lecciones de sociología del individuo. Recuperado de http:// repositorio.pucp.edu.pe/index/handle/123456789/52674

Matos, M., Gonçalves, M. y Maia, Â. (2017). Human Trafficking and Criminal Proceedings in Portugal: Discourses of Professionals in the Justice System. Trends in Organized Crime, 21, 370-400. https://doi.org/10.1007/s12117-017-9317-4

Merton, R. K. (2002). Teoría y estructura sociales. México D.F.: Fondo de Cultura Económica.

Ministerio de Economía y Finanzas (2017). Consulta amigable. Recuperado de http:// apps5.mineco.gob.pe/transparencia/mensual/default.aspx?y=2015\&ap=ActProy

Ministerio de Justicia (Minjus) (2017). ¿Cómo es la trata de personas en el Perú? Recuperado de https:// indaga.minjus.gob.pe/sites/default/files/BOLETIN\%20N01\%20 Trata\%20de\%20 Personas\%20V4.pdf

Ministerio del Ambiente (Minam) (2017). Mapeo y monitoreo de los bosques húmedos amazónicos en el Perú. (Compendio de artículos técnicos y científicos). Recuperado de http:// www.bosques.gob.pe/archivo/Compendio-de-articulos-tecnicos-cientificos.pdf

Ministerio del Interior (Mininter) (2017). Plan Nacional contra la Trata de Personas 20172021. Recuperado de https://www.mininter.gob.pe/sites/default/files/PLAN\%20 NACIONAL\%20CONTRA\%20LA\%20TRATA\%20DE\%20PERSONAS\%20 2017-2021.pdf

Montoya, Y. (2012). Manual de investigación para operadores de justicia durante la investigación y el proceso penal en casos de trata de personas. Recuperado de http://www.oimperu. org/oim_site/documentos/Manual\%20de\%20capacitacion.pdf

Montoya, Y. (2016). El delito de trata de personas como delito complejo y sus dificultades en la jurisprudencia peruana. Derecho PUCP, (76), 393-419. https://doi.org/10.18800/ derechopucp.201601.016

Mujica, J. (2014). Elementos comparados del impacto de la trata de personas en la salud de victimas adolescentes en el contexto de la minería ilegal de oro en Madre de Dios. Lima, Perú: Promsex Centro de Promoción y Defensa de los Derechos Sexuales y Reproductivos.

Mujica, J. y Cavagnoud, R. (2011). Mecanismos de explotación sexual de niñas y adolescentes en los alrededores del puerto fluvial de Pucallpa. Anthropologica, 29, 91-110.

Novak, F. (2009). Trata de personas con fines de explotación laboral: el caso de la mineŕia aurifera y la tala ilegal de madera en Madre de Dios. Lima: Pontificia Universidad Católica del Perú y Organización Internacional para las Migraciones.

Presidencia de la República del Perú (2016). Decreto supremo 034-2016-PCM. Recuperado de http://busquedas.elperuano.pe/normaslegales/declaran-el-estado-de-emergenciaen-once-distritos-de-las-pr-decreto-supremo-n-034-2016-pcm-1383308-1/

Reid, J. A. (2013). Rapid Assessment Exploring Impediments to Successful Prosecutions of Sex Traffickers of U.S. Minors. Journal of Police and Criminal Psychology, 28(1), 75-89. https://doi.org/10.1007/s11896-012-9106-6 
Soifer, H. y vom Hau, M. (2008). Unpacking the Strength of the State: The Utility of State Infrastructural Power. Studies in Comparative International Development, 43(3-4), 219-230. https://doi.org/10.1007/s12116-008-9030-z

Sozzo, M. (2000). Seguridad urbana y tácticas de prevención del delito. Cuadernos de Jurisprudencia y Doctrina Penal, 10, 17-82.

Sistema Peruano de Información Jurídica (SPIJ) (2004). Nuevo Código Procesal Penal. Decreto legislativo 957. Recuperado de http://spij.minjus.gob.pe/CLP/contenidos. dll?f=templates\&fn=default-nuevocodprocpenal. htm\&vid=Ciclope:CLPdemo

Sistema Peruano de Información Jurídica (SPIJ) (2007). Ley N²8950. Ley contra la trata de personas y el tráfico ilícito de migrantes. Recuperado de http://spij.minjus.gob. pe/libre/main.asp

Tiwana, N., Bass, G. y Farrell, G. (2015). Police performance measurement: An annotated bibliography. Crime Science, 4(1). https://doi.org/10.1186/s40163-014-0011-4

Tuesta, D. y Mujica, J. (2015). Problemas en la investigación procesal-penal del feminicidio en el Perú (Tema central). Recuperado de http://repositorio.flacsoandes.edu.ecl handle/10469/7961

van der Watt, M. y van der Westhuizen, A. (2017). (Re)configuring the criminal justice response to human trafficking: A complex-systems perspective. Police Practice and Research, 18(3), 218-229.https://doi.org/10.1080/15614263.2017.1291560

Weber, M. (1993).Economíaysociedad. México D.F.: Fondo de Cultura Económica.

Wilson, J. M. y Dalton, E. (2008). Human Trafficking in the Heartland: Variation in Law Enforcement Awareness and Response. Journal of Contemporary Criminal Justice, 24(3), 296-313. https://doi.org/10.1177/1043986208318227

World Wildlife Fund (WWF) (2017). MAAP \#60: Minería aurifera se incrementa en la zona de amortiguamiento de la Reserva Nacional de Tambopata. Recuperado de http://www.wwf.org.pe/?300873/mineria-auriferaincrementa-zona-amortiguamiento-reserva-nacional-tambopata\#

Yamada, G. (2012). Patrones de migración interna en el Perú reciente. En Empleo y protección social(pp.91-124). Recuperado dehttp://files.pucp.edu.pe/departamento/economia/ LDE-2012-01-04.pdf

Zaffaroni, E. R. (2002). Derecho Penal. Parte General (2a ed.). Buenos Aires: Ediar. 